nitric acid, use part of it, dilute the rest, and pay another freight back to the factory from where it came, as is done where regaining works are used is certainly not economy.

The acidulated water from the drowning-tanks, wash-house, etc., is frequently a source of great annoyance to the nitroglycerol manufacturers. It cannot be let down into running water as it will soon pollute this; it cannot be run into the field as it will soon destroy all vegetation and cause complaint from all sources. If a deep ravine, separated by considerable earth banks from water supplies is to be found on the ground it may be run into that. The ravine, however, ought to be thoroughly cleaned from leaves, etc., and the bottom scraped so as to enable the soil to absorb the water quickly. If limestone of any kind is to be had on the grounds or near by it is certainly the best way to blast a big excavation, fill it with the limestone, and let the wash-water run into this. The limestone will purify the water from adherent nitric and sulphuric acids and affords a good drain for the water.

How far the risks of the dangerous manufacture of nitroglycerol can be minimized may be judged by the fact that since $187 \mathrm{I}$ no accident of any kind, explosion, or fire has taken place at Winterwiken, Stockholm, Sweden. What is of the utmost importance is to have well-constructed plants, good supervision, and a good chemical knowledge.

COLUMBIAN UNIVERSITY, Deceruber, 1894 .

\title{
METHODS FOR THE EXAMINATION OF GLYCEROL FOR USE IN THE NITROGLYCEROL MANUFACTURE.'
}

By G. E. Barton.

Received January 2, 1895 .

THE most commonly accepted methods for the examination of glycerol are described by Allen in his Commercial Organic Analysis, Vol. II.

$\mathrm{H}$ is requirements are very severe, in fact, too severe it seems to me in some respects. For example, he requires entire freedom from chlorides and iron. Most of the glycerol offered to the

1. Read at the Boston Meeting, December 28, 1894 . 
nitroglycerol trade contains both these impurities and, in limited amounts, they are not harmful. $\mathrm{He}$ also requires only feeble reaction with basic lead acetate, yet distilled water gives a decided reaction with this reagent.

It is not possible, using the methods of examination Allengives, to accurately describe a glycerol suitable for the manufacture of nitroglycerol.

The different impurities that such glycerol is liable to contain are :

I. Inorganic bodies, other than sodium chloride, which are shown accurately enough for technical purposes by the ash determination.

2. Sodium chloride.

3. Carbohydrates, sometimes used as adulterants, which are shown by the carbonaceous residue.

4. Fatty acids, either free or combined, a measure for which is found in the total acid equivalent or saponification number.

5. Lighter bodies, mainly hydrocarbons, which influence the permanent specific gravity quantitatively.

The following methods of examination are the result of several years' experience in the examination of glycerol intended for use in the manufacture of nitroglycerol.

Ash and Carbonaceous Residue.-Weigh out between four and one-half and five and one-half grams of glycerol in a tared porcelain capsule and heat cautiously till it inflames. Remove the source of heat and allow it to burn away. Transfer the capsule to a desiccator and, when cold, weigh. This gives the weight of the carbonaceous residue.

The carbonaceous residue ignited gives the ash.

Sodium Chloride. - Take $100 \mathrm{cc}$. of glycerol, transfer to a porcelain casserole, rinse with distilled water, and add the rinsings to the contents of the casserole. Dilute to $300 \mathrm{cc}$, neutralize any free acid with sodium carbonate, add normal potassium chromate solution till the contents of the casserole have a decided yellow color, and titrate with tenth normal silver nitrate solution. After deducting two-tenths cc. required to give the coloration, the remainder is calculated to sodiun chloride. The weight of glycerol taken is calculated from the number of cubic 
centimeters, using the specific gravity at the temperature of the room.

Total Acid Equivalent.-One hundred cc. of glycerol are taken for the determination, transferred to a beaker, made up to about $300 \mathrm{cc}$, a few drops of a one per cent. solution of alcoholic phenolphthalein added, and then ten cc. of normal sodium hydroxide. Boil for a short time and then run in normal hydrochloric acid till the pink color is discharged. The result is expressed in grams of sodium hydroxide required by $100 \mathrm{cc}$. of glycerol.

Higher Fatty Acids.-Pass a stream of nitrogen tetroxide through a portion of the glycerol diluted with twice its volume of distilled water, then heat on a steam-bath for two hours. If there is no precipitate formed, either on diluting or later in the operation, the glycerol may be considered free from higher fatty acids. Glycerol intended for use in the manufacture of nitroglycerol should stand this test.

Neutrality.-A glycerol may be considered neutral if, when fifty cc. are diluted with roo cc. of water and a few drops of an alcoholic solution of phenolphthalein added, not more than three-tenths cc. of normal hydrochloric acid or normal sodium hydroxide solution is required to produce the change in color.

Specific Gravity.-For the specific gravity determination, a Sartorius specific gravity balance is used, and the deternination is made at the temperature of the room. The value found is reduced to the value at $15^{\circ} \mathrm{C}$. by adding a product represented by $(t-15), 0.00065$ and subtracting from this sum a number represented by $0.0003+(t-15) 0.000025 \mathrm{R}$, when $t$ is the teinperature at which the work is done, read from a thermometer in the glycerol, and $\mathrm{R}$ is the value read from the balance.

Permanent Specific Gravity.-Heat a sufficient portion of glycerol for a specific gravity determination in a $250 \mathrm{cc}$. flask for two hours, at a temperature between $225^{\circ}$ and $230^{\circ} \mathrm{C}$. At the end of this time allow the glycerol to come to the temperature of the room, keeping the flask corked with a stopper having a small opening for equalizing the pressure. The specific gravity is then determined as before described. The result is the permanent specific gravity at $15^{\circ} \mathrm{C}$. 
A good sample for nitroglycerol purposes tested as follows: ash, trace; carbonaceous residue, o.or 2 per cent.; sodium chloride, 0.002 per cent.; total acid equivalent, 0.05347 ; permantent specific gravity, 1.2653; specific gravity, 1.2634; higher fatty acids, none; reaction, neutral.

I am inclebted to Dr. Joseph Van Ruymbeke, the inventor of the Van Ruymbeke process of recovering glycerol from soaplyes, for the first idea of the total acid equivalent and permanent specific gravity determinations.

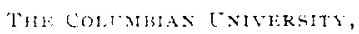

December It, I isy

\section{ESTIMATION OF TELLURIUM IN COPPER BULLION. ${ }^{3}$}

BY CABELL WHTTHEAD.

Recuved January 2, 1895

ISSOLVE from twenty-five to fifty grams of the bullion in $\bigcup$ nitric acid $32^{\circ} \mathrm{B}$. and boil off the excess of acid. Add to this solution an anount of a ferric nitrate solution equivalent to 250 mgms. of metallic iron. Precipitate, while hot, with an excess of ammonia, filter, and wash with dilute ammonia until the copper salts are entirely removed, redissolving and reprecipitating if necessary. The residue on the filter contains the tellurium and sclenium present in the bullion as ferric tellurites and selenites. This is dissolved in hydrochloric acid, and excess of tartaric acid added, the solution made alkaline with potassium hydroxide, and hydrogen sulphide passed through it, when the tellurium and selenium pass into solution as soluble sulphides. Filter; decompose the alkaline sulphides in the filtrate with dilute hydrochloric acid; allow the liquid to stand in a warm place until the hydrogen sulphide has been remored. Filter again; dissolve the tellurium and seleniun sulphides in aqua regia; evaporate the solution to dryness, take up with hydrochloric acid and precipitate the tellurium and seleniun from the solution by passing sulphur dioxide through to saturation. Cover the beaker and allow the solution to stand for twelve hours in a warm place, when the precipitate, which consists of tellurium and selenium, is filtered on a tared filter, dried at $100^{\circ}$, and weighed together.

1 Kead at the Boston Meeting, December 27 . Ints. 